University of Windsor

Scholarship at UWindsor

\title{
The environment, structure, and interaction process of elite same- sex dyadic sport teams
}

T.L. Wickwire

Gordon A. Bloom

Todd M. Loughead

University of Windsor

Follow this and additional works at: https://scholar.uwindsor.ca/humankineticspub

Part of the Kinesiology Commons

\section{Recommended Citation}

Wickwire, T.L.; Bloom, Gordon A.; and Loughead, Todd M.. (2004). The environment, structure, and interaction process of elite same-sex dyadic sport teams. Sport Psychologist, 18 (4), 381-396.

https://scholar.uwindsor.ca/humankineticspub/22

This Article is brought to you for free and open access by the Faculty of Human Kinetics at Scholarship at UWindsor. It has been accepted for inclusion in Human Kinetics Publications by an authorized administrator of Scholarship at UWindsor. For more information, please contact scholarship@uwindsor.ca. 


\title{
The Environment, Structure, and Interaction Process of Elite Same-Sex Dyadic Sport Teams
}

\author{
Tamara L. Wickwire, Gordon A. Bloom, \\ and Todd M. Loughead \\ McGill University
}

\begin{abstract}
The purpose of this study was to examine elite same-sex dyadic sport teams. Semi-structured individual interviews were conducted with elite beach volleyball athletes. The results of the analysis revealed three higher-order categories: (a) sport environment, which included elements related to participation in beach volleyball such as challenges and comparisons between partnerships and other sports; (b) dyad structure and composition, which included individual and relationship elements that created a sense of balance in the partnership; and (c) dyadic interaction process, which focused on developing communication and cohesion in the partnership and working toward an ideal state where interaction was efficient and effective. The results of the study extend group dynamics literature by studying the dyad as a separate group entity and by revealing information specific to this group of athletes.
\end{abstract}

A sport team can be defined as

a collection of two or more individuals who possess a common identity, have common goals and objectives, share a common fate, exhibit structured patterns of communication and modes of communication, hold common perceptions about group structure, are personally and mentally interdependent, reciprocate interpersonal attraction, and consider themselves to be a group. (Carron \& Hausenblas, 1998, pp. 13-14)

Based on the above definition, a dyad is the smallest possible team and is comprised of two communicating individuals (White, 1982). The prevalence

The authors are with the Department of Kinesiology and Physical Education at McGill University, 475 Pine Avenue West, Montreal, Quebec H2W 1S4 CANADA. Email: gordon.bloom@mcgill.ca. 
of dyadic team sports is evidenced by the number of dyadic team events at the Olympic Games. At present, there are 14 dyadic sports included in the Olympic Games, representing a total of 34 different events (Olympic Movement, n.d.). These sports include synchronized swimming, synchronized diving, badminton, beach volleyball, canoeing, kayaking, rowing, sailing, table tennis, tennis, bobsleigh, luge, pairs figure skating, and ice dancing. With such substantial representation at the highest level of sport, it is somewhat surprising that empirical research on dyadic sport teams has received limited attention. One possible explanation for the dearth of research may be the absence of a sport-specific framework related to the study of dyadic relationships (Jowett \& Meek, 2000).

Carron and Hausenblas (1998) outlined a conceptual framework for studying sport teams. The conceptual framework is a linear model comprised of inputs, throughputs, and outputs. Inputs are the attributes of individual group members (e.g., age, personality) and the nature of the group's environment (e.g., group size). The inputs are believed to influence the throughputs, which are comprised of the group's structure (e.g., status, role, norms, leadership), cohesiveness, and processes (e.g., goals, interaction and communication, collective efficacy). Finally, the throughputs lead to the outputs, which are categorized into either individual or team outcomes (Carron \& Hausenblas, 1998). It is important to note that the Carron and Hausenblas model was influenced by McGrath's (1984) general conceptual framework for the study of groups. Not surprisingly, these two frameworks are highly related and closely linked to one another. The two main differences between these frameworks are the inclusion of group cohesion in Carron and Hausenblas' framework, as well as the linear nature of Carron and Hausenblas' framework compared to the cyclical nature of McGrath's framework.

The majority of research related to the factors in the Carron and Hausenblas (1998) framework has focused on team rosters containing more than two group members. For instance, research conducted in sport settings has examined rugby (e.g., Kozub \& Button, 2000; Terry et al., 2000), football (e.g., Westre \& Weiss, 1991), cricket (e.g., Prapavessis \& Carron, 1997), soccer (e.g., Eys, Hardy, Carron, \& Beauchamp, 2003), baseball/softball (e.g., Shields, Bredemeier, Gardner, \& Bostrom, 1995), and volleyball (Brawley, Carron, \& Widmeyer, 1993). More precisely, no research has examined sport teams containing only two members (i.e., a dyadic sport team). This is somewhat unfortunate since empirical evidence has shown that group size influences group-related factors. For example, Widmeyer, Brawley, and Carron (1990) found that teams consisting of three players had higher cohesion than nine-player teams in a 3-on-3 basketball league. Similarly, Carron, Brawley, and Widmeyer (1990) found that exercisers' satisfaction decreased with increasing class size. Given that research related to Carron and Hausenblas' framework has focused extensively on teams with more than two members, and that the size of the group influences group-related variables, research examining dyads seems warranted in sport.

As it stands, research on dyads in sport has been primarily limited to examining the coach-athlete relationship. Overall, the results suggested the coachathlete relationship was important in achieving athletic success (Jowett, 2003; Salminen \& Liukkonen, 1996; Smith \& Smoll, 1996). However, several researchers (e.g., Fisher, Mancini, Hirsch, Proulx, \& Staurowsky, 1982; Miller, Salmela, \& Kerr, 2002) noted that since coaches are designated as formal leaders, they have a stronger basis to exert influence over their athletes, both on a professional and 
personal level. In fact, Miller et al. likened the coach-athlete relationship to that of a mentor-protégé relationship. In the mentor-protégé dyad, the mentor acts as a role model and guides the protégé's development.

Although the coach-athlete dyad relationship is an important one, there is another type of dyadic relationship in sport where both athletes are viewed as equalstatus (i.e., a partnership). To date, very little research attention has been given to these partnership relationships in sport. Outside of sport, however, research on partnership relationships exists. For example, research in social psychology found that dyads have special characteristics, such as greater pressure and influence in decision making, which differentiated them from larger groups (Hare, Blumberg, Davies, \& Kent, 1994). Research on the social psychological attributes of dyadic participants found the performance of dyads was better if members liked each other (Krivonos, Byrne, \& Friedrich, 1976). Along the same line, perceptions of equal status between members were found to be important, especially in competitive situations (Tjosvold, 1981). More precisely, the more similar the two members of a team were in ability, the more likely they were to form an effective team. Yet, the relationship between member abilities and group performance has revealed equivocal results (Comrey \& Staats, 1955; Gill, 1979).

In sum, there exists sufficient non-sport research on various elements of the dyadic relationship. However, participants in the majority of these studies met in highly controlled laboratory settings, had little emotional investment in the relationship, and interacted for a very short time period (i.e., a few hours). This contrasts with dyadic athletes who have been paired together through countless tryouts, invested a great deal of time and effort in training and competing, have set long term goals together, and have established a close personal relationship over many months, if not years. Thus, the purpose of the current exploratory study was to examine elite dyadic sport teams. Using the Carron and Hausenblas (1998) conceptual framework as a guide, this study identified the composition (e.g., athlete characteristics), structure (e.g., status, role, leadership), and key elements (e.g., cohesion, communication) inherent with elite same-sex dyadic sport teams.

\section{Method}

\section{Participants}

Elite same-sex dyadic sport athletes participated in this study. Specifically, seven international level beach volleyball athletes were interviewed. Two of the participants were female and five were male. All participants had competed at the international level and were ranked in the top 45 beach volleyball teams in the world. Several athletes had also competed at the Olympic Games. Both members of each dyad were interviewed individually (only one partner of one team was available, which accounts for the uneven number of participants). A summary of the participants' background and experience is found in Table 1.

\section{Instrument and Procedure}

The athletes were identified by administrators at Volleyball Canada. All participants were contacted by e-mail and informed of the nature of the investigation and invited to participate. They were selected based on a top 50 world ranking and a minimum of five years involvement in dyadic sport partnerships. It was not necessary for 
Table 1 Athlete Information and Experience

\begin{tabular}{clcccc}
\hline Athlete & Years & $\begin{array}{c}\text { Years } \\
\text { experience } \\
\text { number }\end{array}$ & Gender & $\begin{array}{c}\text { Years } \\
\text { experience } \\
\text { in volleyball } \\
\text { volleyball }\end{array}$ & $\begin{array}{c}\text { Years with } \\
\text { sport teams } \\
\text { surrent } \\
\text { partner }\end{array}$ \\
\hline A1 & Female & 12 & 5 & 5 & 3 \\
A2 & Female & 7 & 6 & 6 & 3 \\
A3 & Male & 12 & 10 & 10 & 1 \\
A4 & Male & 16 & 8 & 8 & 1 \\
A5 & Male & 11 & 11 & 11 & 7 \\
A6 & Male & 16 & 15 & 12 & 8 \\
A7 & Male & 18 & 14 & 14 & 8 \\
\hline
\end{tabular}

each athlete to have been with the same partner for the five years. As well, the participants were required to have competed at the international level in their dyadic sport. Also, all participants had between seven and 18 years of experience playing volleyball $(M=13.1)$, as well as other larger team sports.

A four-part interview guide with a series of open-ended questions was created specifically for this study. The first part, an introductory question (e.g., "How did you get involved in your sport?"), was designed to initiate the discussion as well as preface the main topic. The second part consisted of nine key questions developed from the Carron and Hausenblas (1998) framework. The key questions focused on personality traits or characteristics of dyadic sport teams, as well as cohesion, communication, and the nature of the dyadic relationship, which included similarities, differences, and challenges of two-person sport teams. The third part consisted of a summary question that tied together the most important points (e.g., "What are the key elements that characterize a dyad?"), and the fourth part included a concluding question that gave the participants the opportunity to add any additional information. Interview probes and follow-up questions were implemented to add depth and clarity to the participants' answer, to pursue the central themes discovered, to elaborate on the context of answers, and to explore the implications of what had been said (Rubin \& Rubin, 1995). Each individual interview lasted between 60 and 90 minutes and took place at a mutually convenient location in either Montreal or Toronto, Canada.

Each interview session began with informal conversation designed to put the participant at ease (Fontana \& Frey, 1994). The principal investigator directed the informal talk toward the topic and set the tone for the rest of the interview (Rubin \& Rubin, 1995). At this time, the respondents read and signed a consent form and completed a short demographic questionnaire. The principal investigator informed the participant that the interview would be audio recorded and that a full verbatim transcript would be sent back to him or her for approval and editing before it was analyzed. The audio recording began at this point. The participant's confidentiality was protected through the use of a coding system that replaced each name with a 
number (i.e., \#1-7); as well, any potentially identifying information (e.g., name of coach, home town) was also replaced or disguised.

\section{Data Analysis}

The procedures outlined by Côté, Salmela, and Russell (1995) were used to analyze the interview data. Côté and colleagues' method of analysis consists of three main steps: creating tags, creating properties, and creating categories.

To begin, the interviews were transcribed verbatim with only minimal editing, such as removing personal information to ensure confidentiality. Then, the transcripts were divided into 480 quotes called meaning units (MU), which were separate pieces of text containing one idea, concept, or piece of information (Tesch, 1990). At the same time, each meaning unit was given a tag based on its content. A tag was a descriptive name for the meaning unit. A total of 60 tags emerged from the data. Following this, the tags were listed, compared, and then combined into distinct higher-order groups called properties. Properties were named according to the common features their tags shared. In this stage, the 60 tags were grouped into nine properties. The final stage of analysis involved regrouping the properties identified in the previous stage into broader conceptual categories. The data were examined until saturation was reached and no new levels of information emerged at each of the levels (Côté et al., 1995). By the final stage of analysis, the nine properties had been organized into three larger categories.

\section{Trustworthiness}

The trustworthiness of this analysis was increased by following the suggestions forwarded by Lincoln and Guba (1985), Rubin and Rubin (1995), and Sparkes (1998). First, member checks were used to allow the participants to verify the researchers' understanding of the information they have provided (Lincoln \& Guba, 1985). A full verbatim transcript of the interview was provided for each participant, giving them the opportunity to correct errors of fact, clarify ambiguous information, and volunteer additional information. This process provided the researcher with the opportunity to review the accuracy of the data, which is the first step in data analysis according to Lincoln and Guba. Furthermore, after the data had been analyzed, each participant was sent a summary of the results, conclusions, and a visual diagram to review and add any comments, corrections, or areas requiring clarification. Five of the seven participants completed the member check. The participants confirmed the correctness of the information sent to them, thus assuring the research team that the results were accurate.

Second, peer review was used to improve the credibility of this study (Lincoln $\&$ Guba, 1985). The peer review process took place independently of the principal researcher. A peer assistant examined $25 \%$ of the meaning units created from the data and matched each meaning unit with a tag previously established by the researcher. The peer assistant matched the meaning units with the tags based on what he or she felt were the most appropriate combinations. A reliability rate of $88 \%$ was achieved. After discussion between the researcher and the peer assistant, it was agreed that seven of the tags would be recoded because the original tags did not adequately reflect the meaning in the passages with that tag. Of that seven, four were split into two meaning units instead of one. This procedure also took place when the properties and categories were created. The peer assistant classified 
the 60 tags into nine properties. An $87 \%$ rate of reliability was achieved. Again, consensus was reached after discussion. Of the seven that were not in agreement, five were recoded and two remained as they were. All discrepancies in classification between the principal researcher and the peer assistant were discussed until a common understanding was reached. A reliability rate of $100 \%$ was then achieved for the categories.

Third, thick descriptions of the participants' thoughts are provided in the results section by including appropriate MU in order to help the reader interpret the data (Sparkes, 1998). Finally, the trustworthiness of this study was enhanced by the first author becoming familiar with beach volleyball by reading books and articles on the sport and by attending the participants' practices as well as several games and tournaments. This also helped build rapport between the interviewer and interviewees (Rubin \& Rubin, 1995). Additionally, the principal researcher participated in dyadic sports for 10 years as an athlete and as a coach.

\section{Results}

A total of 480 meaning units emerged from the seven interviews. From this, three higher-order categories emerged from the data, which identified and described elements of elite dyadic sport teams. The categories were called sport environment, dyad structure and composition, and dyadic interaction process. Each category will be explained in the following section.

\section{Sport Environment}

Sport environment included elements related to the sport of beach volleyball as well as the unique challenges a partnership sport, in particular beach volleyball, presented. It was the basis for understanding a sport partnership and the nature of being a dyadic sport athlete. The sport environment was comprised of three properties: sport/beach history/issues, comparing partnerships and other sports, and other partners/partnerships.

Sport/beach history/issues involved the sporting background of each athlete as well as how they got involved in beach volleyball. The most common response was, "I got involved with beach volleyball like most other athletes in my sport, through playing volleyball" [A7]. Information also emerged relating to the amount of time each team had spent together:

I think my partner and I are the longest playing team; we've played the most international teams together in the world. There is a website that keeps track of these stats, and we have played over 100 international tournaments, which ranks us number one. [A6]

As well, the unique challenges faced by beach volleyball athletes were discussed in this property, such as limited coaching availability:

A big difference in our sport is that it is prohibited to use a coach during a game. We deal with things ourselves. .. . There are no books written and nobody that can tell you what to do. In tennis, every aspect of the game is studied; all you have to do is play 
the best you can. For us, everybody in the world is still learning the sport because it is so young. [A3]

Another beach volleyball issue that emerged was the large amount of international travel. The following MU provided an example of this dimension:

With the schedule on the international tour, we're traveling all the time. We have 11 tournaments in 13 weeks, which is a lot. We stay in a country for seven to ten days. When we are there, we are just training — that's it. Then we travel to other events. [A1]

Comparing partnerships and other sports alluded to the similarities and differences between pairs and individual sports, as well as between pairs and larger team sports. All of the athletes in the current study had competed in individual, partnership, and team sports. The participants felt the dynamics of being in a relationship was the primary difference between pairs and an individual sport. For instance, the participants highlighted the importance of sharing responsibility for actions and outcomes, having to depend on someone else, and dealing with someone else's emotions and problems. The participants also discussed a number of differences between pairs and larger team sports, with the main difference being the intensity of the relationship in a pairs sport. The following quotation highlighted this point by focusing on the differences that occurred as a result of being in a partnership:

The biggest difference I can think of is the relationships that happens. On a team, you have got ten people and that one person has a relationship with nine different people. It gets very, very complicated and usually there are a few who are always butting heads. That's one of the great things about beach volleyball; there is only one person you have to worry about. There are not all these other relationships that come in and damage it in a negative way. [A5]

Other partners/partnerships included the challenge of finding the right partner. "You have to match your strengths and weaknesses and you have to make sure that his style goes with your style and that you're as strong mentally" [A3]. Also included were the reasons for separating from a previous partner. For example, one athlete talked about a drug dependency of a previous partner:

Once I was playing with one guy and I could see something was wrong with him. I joked to him and said, "Are you on drugs or something?" I found out afterwards that he was smoking up before the finals and that really ticked me off. I knew this guy wasn't right for me and I got rid of him even though he was an awesome player; he was just in the wrong crowd. [A5]

Along the same line, information emerged regarding negative interactions with different partners and within other teams. The following quotation addressed some of the potential problems and demonstrated how difficult it can be to find a good match between two individuals: 
It is how you work together with the relationship. It is how you talk to each other, push each other, and work together. If I push you, do you fold? It's all of these things. I can't really describe what they are, it's a feeling, it's weird . . like sensing and feeling the other guy. I tried out with two other guys and I just sensed they weren't right. It's how they spoke and communicated. [A5]

\section{Dyad Structure and Composition}

Dyad structure and composition included both individual and relationship elements that were specific to a partnership. The importance of particular member characteristics and the compatibility of those elements within the dyad were described by the participants. As well, this category alluded to the course of a dyad's development and evolution, including when and how dyad participants spent their time together. In particular, three properties were included in this category: time with partner, personality traits, and interpersonal development.

Time with partner included time spent together throughout the entire year, both inside and outside of sport. Although the amount of time partners spent together varied with each partnership and the time of the year, the overall amount of time was substantial and encompassed a large part of each individual's life. "We spend a lot of time together ... I would say 30 hours a week with everything together, including mental training, training on the court, and weight training" [A4].

Personality traits consisted of the different qualities and characteristics that were important for a beach volleyball athlete individually, as well as the traits and attitudes that were desirable in a partner. Important traits and/or attitudes for a beach volleyball athlete included being flexible, confident, and competitive. The following quote demonstrated the process of adapting to the traits and attitudes of a partner:

There has to be a little bit of everything between the two athletes and that is why my partner and I work well together. He is kind of a leader and he likes to feel that way and he's pretty opinionated and has his way of doing things and I think that the team benefits from that kind of attitude. He is also like that on the court. So he'll stand up for the team when it's the right time to erupt. He'll take the leadership role there and I think the team needs that. [A6]

Interpersonal development involved developing the relationship and creating a sense of balance in the partnership. It was the give and take that developed on and off the court, the factors that contributed to development, and the byproduct of that development. The following off-court example brought this information to light:

I think just spending that much time together, there's a lot of times when, "oh that's frustrating me" or "that bothers me," so I think you have to remember, okay, well there's no use getting into an argument about a stupid little thing like the fact that my partner opens the blinds at 6:30 in the morning every time he wakes up. There's no use getting into a full-blown argument about that when you're there to perform the next day. So you talk about it 
and just say "you know, that's kind of bothering me." There's pressure leading up to an event and it's easy to get agitated about little things like that. [A6]

This property also included information pertaining to complementing and compensating for their partner, accepting their partner's weaknesses and differences, and accommodating and making concessions in the relationship. Aspects of this are evidenced in the following two quotes:

Your partner's performance is a factor on your strategy, and how you set up your team. I have to take into consideration what my strengths are, what my partner's strengths are, what his weaknesses are, what my weaknesses are, and come up with the best way to set up our team for that game. For example, we were both defensive players when we started out but my partner's a smaller player than I am, and isn't as big at the net. I had to assume a different role because I know it makes us better. If I play with somebody who's a bigger player than me or a bigger jumper, I would be in the defensive role. So I've had to change my role on the team because it makes our team stronger and that's the kind of thing you have to work with in pairs. [A7]

This year my partner and I started our fourth year playing together. The first year we had to make adjustments for everything because we didn't know each other. The second year was better because I began to know how she plays on the court. I'm a defender player so I know that I can take a lot of space on the court and she's moving in that way and I know that. This is the fourth year and we don't have to talk a lot. I know if I'm defending a ball, she will do that and I will do that . . . the best teams don't have to say a word in the game because they know each other perfectly. [A2]

\section{Dyadic Interaction Process}

The dyadic interaction process comprised the key elements of a sport partnership that allowed the team to move to an advanced, more effective level of interaction. It involved the exchange of information that occurred in all contexts of the partnership, the coming together of the team, and the resulting unity, consistency, solidarity, and organization of the team. The dyadic interaction process followed the dyad structure and composition, which provided the groundwork for a partnership to really flourish. In the dyad structure and composition, all of the primary and practical elements such as time together, personality traits, and basic interpersonal development issues were worked out, which led into the next natural stage of partnership development - the interaction process. The properties that made up this category were being on the same page, communication, and cohesion.

Being on the same page was characterized by having confidence in their partner's choices and suggestions and believing they both had the same goals and commitment. An example of this dimension can be seen in the following MU: 
If a volleyball player asked me about becoming an elite beach volleyball player, all I would say to them is you've got to find somebody who's on the same page and has the same goals as you. For example, if I just want to win some lower-level thing, and that's all I want to do, but your goal is to make the Olympics, well you're not on the same page right off the bat. You've got to make sure you have somebody who's willing to say, "hey I want to travel internationally, I want to come top four in Canada and then go represent Canada internationally." [A5]

This property also involved a higher-level connection between the partners compared to what was found during the interpersonal development stage (which was described in the previous category). The dyad had established its unique culture at this point and was now seeking to develop beyond the surface relationship in order to achieve greater success on the court. The following quotations highlighted the importance of knowing, believing, and trusting your partner:

If you don't believe in your partner, you cannot win. Your partner is very important because they are the other half. I think believing in your partner is more important than believing in yourself. If you don't have confidence in your partner, you should not play with her. [A2]

It's hard to do in the beginning - to listen to your partner and do it. If you have something in your mind like hitting across, and you hear your partner call "line," you know you have the choice. You either do what you want to do or you have to be confident in your partner and do what she tells you. It depends on the situation but usually I would listen to the call she makes. [A1]

An aspect of being on the same page was communication. The current results highlighted the importance of communication in a relationship and how it developed. This involved listening to their partner, taking their advice or criticism, and making decisions with them. The following quotations related to specific oncourt elements of communication:

On-court communication for beach volleyball is key; there are only two of you and there's a big court, so to communicate well during the game and through the systems that you have, I think that's a big part of our sport. You need to communicate and let them know where you are on the court at all times and that comes with experience. [A6]

You have to be able to take the comments of the other person. It is not easy to talk to your partner on the court if she is not playing well. You don't have a coach, so you have to say or do something. Sometimes with the pressure and the action you might say "do it like that" or something a little bit rough and you don't mean it to be. If the other person can't take that 
and she gets very upset about what you said, then chemistry will be no good, and so will the game. I think you have to be able to take the comments. [A1]

The athletes in the study also discussed various elements of off-court communication. Examples of this form of communication can be seen in the following quote:

We e-mail each other every day. We talk about strategy, what kind of training we're going to do over the weekend, things like that. It's about training, about what's happening in our lives. If you happen to be feeling bad one weekend because of your girlfriend or your job situation or your health, whatever, you still have to be able to perform and train and the other guy has to know why and help you with it. [A3]

Although cohesion is being described after communication in this instance, the two were viewed as co-dependent and equally important. This property involved the importance of cohesion in a partnership, ways to develop it, and the effects it had on the partnership when it was strong or weak. It was difficult to determine whether cohesion (task or social) followed from good communication or vice versa because they were so closely related, but in many ways cohesion seemed to be the byproduct of a solid structure and composition, as well as a system of good communication in a partnership. The following quotation highlighted elements of social cohesion:

Cohesion develops by repetition on the court and by spending a lot of time together off the court, either playing other sports, going out to clubs, or eating out. It is just spending time together getting to know the other person. [A3]

Elements of task cohesion were also discussed by the current participants, as evidenced in the following quotation:

I don't know why (some teams stick together who don't like each other). I know some teams who don't talk to each other at all. They don't live in the same place or stay in the same hotel. However, on the court, they are the best partnership - they are very good. When I look at them, I just don't know how they can do that, as I never could. [A1]

\section{Discussion}

The purpose of the current study was to examine elite same-sex dyadic sport teams using Carron and Hausenblas' (1998) conceptual framework as a guide. Overall, three main areas emerged from the analysis of the data: sport environment, dyad structure and composition, and dyadic interaction process. The results of the current study will first be discussed in relation to Carron and Hausenblas' conceptual framework, followed by a discussion of the three categories. The article 
will conclude by discussing limitations and future recommendations, as well as practical implications of this study.

From a conceptual standpoint, the results of the present study offered empirical support for Carron and Hausenblas' (1998) model as a basis for examining dyadic sport teams. These findings revealed the components of the linear model (i.e., inputs, throughputs, and outputs) were relevant to dyadic sport teams. More importantly, the participants highlighted the factors contained within each of the components of the model. The input factors relating to the group's composition and the group's resources were salient to the effective functioning of a dyadic relationship. For instance, the athletes noted that it was important to have a partner that had personality traits compatible with their own personal characteristics. As well, the participants noted the unique nature of having only two group members influenced the team's functioning by increasing the pressure and responsibility they felt to the partnership.

Throughputs, the next component of Carron and Hausenblas' (1998) conceptual framework, are comprised of team structure, cohesion, and group processes. Team structure is comprised of such factors as roles, norms, and leadership - all of which played an integral part in the functioning of dyadic team sports. For example, since there were only two team members, leadership within the team was viewed as a shared experience, depending on the nature of the situation. Another throughput, cohesion, was also deemed important by the athletes in the current study. In particular, they emphasized the importance of fostering cohesion and methods used to develop both task and social cohesion, such as spending time in social situations and focusing on task-related aspects on the court. Consequently, the results concurred with Carron, Brawley, and Widmeyer's (1998) multidimensional conceptualization of cohesion. The final throughput, group processes, also emerged in the current study. More specifically, the results indicated that team goal setting (i.e., both partners having the same goal) and being committed to reaching these team goals were important to the development of dyadic teams.

The findings of the current study suggested that the intensity of the dyadic relationship was one of the most significant differences between a dyad and a larger team (e.g., traditional volleyball team). The results revealed that athletes felt greater pressure and responsibility in a partnership compared to larger teams, in part because they had more influence in decision making, as well as more control over the outcome of a contest in a dyadic group. These findings were comparable to research by Widmeyer et al. (1990) indicating that a team member's perception of influence and responsibility was highest on smaller teams comprised of three individuals compared to teams of six and 12 group members. Since the environment was comprised of only two individuals, each person played a larger role in contributing to the make-up of the environment. The heightened perception of pressure and responsibility in dyadic sport teams may be explained by the number of partners the participants in the study went through before they were able to find a match with which they were satisfied.

The results of the present study suggested that some of the member attributes were similar in dyads compared to larger team sports; these included being flexible, confident, competitive, and displaying effective leadership skills. However, some of the findings were unique to dyads. For example, having both a team-oriented 
attitude along with an independent attitude was particularly important to athletes in dyads. This may have been due to the unique group structure found in dyads whereby the partnership relationship requires a high level of cooperation between members as well as a high degree of personal responsibility for the outcome of the games. Previous research in this area found that team sport athletes were more dependent on others, while individual sport athletes showed more independence (Schurr, Ashley, \& Joy, 1977).

Analysis of the current findings revealed that communication, cohesion, and goals were important components of the dyadic interaction process. Communication played a critical role given the enormous influence each member had on the other. The interaction in a dyad was only between two members, and thus the intensity between members necessitated effective, efficient, and positive communication on a continuous basis. This was comparable to Burgoon, Heston, and McCroskey's (1974) findings that communication in small groups was influenced by how members transmitted information to one another.

With respect to cohesion, the current results were similar to Carron, Colman, Wheeler, and Stevens' (2002) findings that task and social cohesion were positively associated with performance. In the present study, strong task and social cohesion created a synergy within the dyad that was reflected in a better on-court performance as well as a more positive relationship off court. In contrast, the participants noted that weak cohesion had a noticeable negative impact on performance and on the social relationship.

Having both members of a dyad share similar goals was another important factor in the dyadic interaction process. This compares to Mills' (1984) suggestion that group goals are simply not the sum of personal goals of team members but are shared perceptions that help improve team functioning. This point was evident in the current study whereby both members of the team worked together to achieve team goals. Furthermore, the participants felt that partnerships would be more likely to split up if there was not a shared vision of the teams' goals.

This was an exploratory study into various factors specific to elite dyadic sport teams. Since all participants were beach volleyball players, one must exercise caution when generalizing these results across other dyadic sport teams. As a result, the current study should be replicated with other dyadic sports. As well, it would be worthwhile to examine elements of dyadic teams competing at other levels, such as high school and state/provincial, to determine which elements are the most prevalent. Given the small sample of females $(n=2)$, gender differences between female teams, male teams, and even mixed gender teams could also be investigated. Research has shown that cohesion in female teams is more strongly related to performance than in male teams (Carron et al., 2002). Therefore, it seems warranted to examine whether there are any differences in male, female, and/or mixed gender team dyadic sports and, if so, what type of events are associated with higher cohesion and its impact on performance.

The results of the present study could not determine whether increased cohesion was a byproduct of effective communication or vice versa. This finding is similar to results from a recent meta-analysis examining the cohesionperformance relationship in sport (Carron et al., 2002). In an examination of the direction of the cohesion-performance relationship, Carron et al. found no 
differences in cohesion acting as cause of performance or cohesion acting as a result of performance. That is to say, cohesion contributed to better performance and, similarly, better performance contributed to cohesion. Perhaps a similar temporal effect exists in the communication-cohesion relationship whereby cohesion enables effective communication and, likewise, effective communication enhances cohesion.

The findings from the current study offer several implications for elite same-sex dyadic sport athletes to achieve both personal and performance-based satisfaction. First, before committing to a partner, these athletes should spend considerable time together to make sure they are compatible on both a task and social level. Moreover, they must have the same goals and vision. Second, these athletes must recognize the importance of compromising, accommodating, and making concessions for the good of the partnership. This can be accomplished through open and frequent communication. Third, these athletes must recognize the importance of task and social cohesion, which can be accomplished through team goal setting (i.e., task cohesion) and spending free time together off of the court (i.e., social cohesion).

In summary, dyadic sports are starting to receive increased attention around the world as evidenced by more events at the Olympic Games, increased exposure from the media, and greater rates of participation in many dyadic sports, including beach volleyball. It is our hope that researchers will recognize the importance of studying the dyad as a separate group entity and begin to explore other aspects of the dyadic sport team and/or athlete.

\section{References}

Brawley, L.R., Carron, A.V., \& Widmeyer, W.N. (1993). The influence of the group and its cohesiveness on perceptions of group-related variables. Journal of Sport and Exercise Psychology, 15, 245-260.

Burgoon, M., Heston, J.K., \& McCroskey, J. (1974). Small group communication: A functional approach. New York: Holt, Rinehart \& Winston.

Carron, A.V., Brawley, L.R., \& Widmeyer, W.N. (1998). The measurement of cohesiveness in sport groups. In J.L. Duda (Ed.), Advances in sport and exercise psychology measurement (pp. 213-226). Morgantown, WV: Fitness Information Technology.

Carron, A.V., Brawley, L.R., \& Widmeyer, W.N. (1990). The impact of group size in an exercise setting. Journal of Sport and Exercise Psychology, 12, 376-387.

Carron, A.V., Colman, M.M., Wheeler, J., \& Stevens, D. (2002). Cohesion and performance in sport: A meta analysis. Journal of Sport and Exercise Psychology, 24, 168-188.

Carron, A.V., \& Hausenblas, H.A. (1998). Group dynamics in sport (2nd ed.). Morgantown, WV: Fitness Information Technology.

Comrey, A.L., \& Staats, C.K. (1955). Group performance in a cognitive task. The Journal of Applied Psychology, 39, 354-356.

Côté, J., Salmela, J.H., \& Russell, S. (1995). The knowledge of high-performance gymnastic coaches: Methodological framework. The Sport Psychologist, 9, 65-75.

Eys, M.A., Hardy, J., Carron, A.V., \& Beauchamp, M.R. (2003). The relationship between task cohesion and competitive state anxiety. Journal of Sport and Exercise Psychology, 25, 66-76. 
Fisher, A.C., Mancini, V.H., Hirsch, R.L., Proulx, T.J., \& Staurowsky, E.J. (1982). Coachathlete interactions and team climate. Journal of Sport Psychology, 4, 388-404.

Fontana, A., \& Frey, J.H. (1994). Interviewing: The art of science. In N.K. Denzin, \& Y.S. Lincoln (Eds.), Handbook of qualitative research (pp. 361-375). Thousand Oaks, CA: Sage

Gill, D.L. (1979). The prediction of group motor performance from individual member ability. Journal of Motor Behavior, 11, 113-122.

Hare, A.P., Blumberg, H.H., Davies, M.F., \& Kent, M.V. (1994). Small group research: A handbook. Norwood, NJ: Ablex Publishing Corporation.

Jowett, S. (2003). When the "honeymoon" is over: A case study of a coach-athlete dyad in crisis. The Sport Psychologist, 17, 444-460.

Jowett, S., \& Meek, G.A. (2000). The coach-athlete relationship in married couples: An exploratory content analysis. The Sport Psychologist, 14, 157-175.

Kozub, S.A., \& Button, C.J. (2000). The influence of a competitive outcome on perceptions of cohesion in rugby and swimming teams. International Journal of Sport Psychology, 31, 82-95.

Krivonos, P.D., Byrne, D., \& Friedrich, G.W. (1976). The effect of attitude similarity on task performance. Journal of Applied Social Psychology, 6, 307-313.

Lincoln, Y.S., \& Guba, E.G. (1985). Naturalistic inquiry. London: Sage.

McGrath, J.E. (1984). Groups: Interaction and performance. Englewood Cliffs, NJ: Prentice-Hall.

Miller, P.S., Salmela, J.H., \& Kerr, G. (2002). Coaches' perceived role in mentoring athletes. International Journal of Sport Psychology, 33, 410-430.

Mills, T.M. (1984). The sociology of small groups (2nd ed.). Englewood Cliffs, NJ: Prentice Hall.

Prapavessis, H., \& Carron, A.V. (1997). Sacrifice, cohesion, and conformity to norms in sport teams. Group Dynamics: Theory, Research, and Practice, 1, 231-240.

Rubin, H.J., \& Rubin, I.S. (1995). Qualitative interviewing: The art of hearing data. London: Sage.

Salminen, S., \& Liukkonen, J. (1996). Coach-athlete relationship and coaching behavior in training sessions. International Journal of Sport Psychology, 27, 59-67.

Schurr, K.T., Ashley, M.A., \& Joy, K.L. (1977). A multivariate analysis of male athlete characteristics: Sport type and success. Multivariate Experimental Clinical Research, 3, 53-68.

Shields, D.L., Bredemeier, B.J., Gardner, D.E., \& Bostrom, A. (1995). Leadership, cohesion, and teams norms regarding cheating and aggression. Sociology of Sport Journal, 12, 324-336.

Smith, R.E., \& Smoll, F.L. (1996). The coach as the focus of research and intervention in youth sports. In F.L. Smoll \& R.E. Smith, (Eds.), Children and youth in sport: A biopsychosocial perspective (pp. 125-141). Dubuque, IA: McGraw-Hill.

Sparkes, A.C. (1998). Validity in qualitative inquiry and the problem of criteria: Implications for sport psychology. The Sport Psychologist, 12, 363-386.

Terry, P.C., Carron, A.V., Pink, M.J., Lane, A.M., Jones, G.J.W., \& Hall, M.P. (2000). Perceptions of group cohesion and mood in sport teams. Group Dynamics: Theory, Research, and Practice, 4, 244-253.

Tesch, R. (1990). Qualitative research analysis types and software tools. New York: Falmer. 
The official website of The Olympic movement. (n.d.). Retrieved June 19, 2002, from http: //www.olympic.org

Tjosvold, D. (1981). Unequal power relationships within a cooperative or competitive context. Journal of Applied Social Psychology, 11, 137-150.

Westre, K.R., \& Weiss, M.R. (1991). The relationship between perceived coaching behaviors and group cohesion in high school football teams. The Sport Psychologist, 5, 4154.

White, J.M. (1982). Dyadic systems analysis. Behavioral Science, 27, 104-117.

Widmeyer, W.N., Brawley, L.R., \& Carron, A.V. (1990). The effects of group size in sport. Journal of Sport and Exercise Psychology, 12, 177-190.

Manuscript submitted: October 27, 2003

Revision received: April 26, 2004 